\title{
Analysis of Tear Fluid for Evaluation on the Concentration of the Generic Anti-Glaucoma Drug Betoptik using Multisensory Stripping Voltammetry and Multivariate Statistics
}

\author{
I. I. Kolesnichenko ${ }^{1}$, L. M. Balashova $a^{2,3}$ \\ ${ }^{1}$ Frumkin Institute of Physical Chemistry and Electrochemistry, Russian Academy of Sciences, RU-119071, Moscow, Russia \\ ${ }^{2}$ Pirogov Russian National Research Medical University, RU-117997, Moscow, Russia \\ ${ }^{3}$ International Research and Practice Center for Tissue Proliferation, Non-commercial Partnership, RU-119034, Moscow, Russia
}

\begin{abstract}
It is important to monitor the concentration of drugs after their instillation: this helps to find the right drug dosages. The proposed method is based on recognizing multidimensional images through the use of multidimensional statistics; the images are produced by multisensory electrochemical systems that provide reliable information about the tested objects. The measurements were carried out using a planar solid-state electrode. The test-system solution was a $0.05 \mathrm{M} \mathrm{KCl}$ solution, which contained the $\mathrm{Zn2+,} \mathrm{Cd} 2+$, $\mathrm{Pb} 2+, \mathrm{Cu} 2+\mathrm{Co} 2+$, and $\mathrm{Hg} 2+$ metal cations at the concentration of 5 10-5 M. A new electrochemical method for multisensory stripping voltammetry has been used to determine whether it is appropriate for determination of generic forms of the drug Betoptic, that is, Xonef, Betoftan, and Betalink EU in tear fluid. Measurements were carried out on a planar three-electrode interdigitated electrode. It has been shown that this method is effective for determination of the generics. The dynamics of changes in their concentrations over time were examined. After instillation of the generics in glaucoma patients, their concentrations in the Tear fluid remained unchanged within $12 \mathrm{~h}$. The list of organic substances that can be determined by the method of multisensory stripping voltammetry has been extended.
\end{abstract}

\section{Introduction}

Composition of blood is always critically important. Its resilience has been studied in some detail including the active reaction $(\mathrm{Ph})$, the ratio of electrolytes, glucose, and number of the formal elements and others. Due to the intensive development of high-tech methods for research in the modern world, there already exist large diagnostic capabilities. However, a large amount of information we always need to get is often unavailable. This raises the question about meaningful etiopathogenic using these techniques, especially in ophthalmology, because as of today there is no simple, informative and pathognomonic method for early diagnosis of ophthalmological diseases. Data needed for the studying of the effectiveness of these techniques are quite limited, and their efficiency in diagnosing different ophthalmic pathologies practically is not well studied that makes it difficult to determine their role. The medical and social importance of such pathologies as glaucoma, myopia, retinopathy and AMD (agerelated maculardegeneration) are indisputable so as and the early diagnostic of these diseases. Despite the numerous methods of diagnosis and treatment of these deceases, blindness and a high level of disability resulting from these ophthalmic pathologies are still a global problem. In this work, we propose an innovative method which is neither expensive and nor time consuming and easy to use. As a primary method, we use multisensory stripping (thick-film electrode) voltammetry (IVA) to determine the status of the homeostasis of the organism as a whole, assessing whole blood or serum and local homeostasis, appreciating the tear fluid of the anterior chamber of the eye and the vitreous. This allows tracng the evolution of biological fluids depending on the evolution of the pathological process. Built on the express-diagnostics of biological fluids, the method will be used for the preliminary assessment of various conditions. A method for recognition of multidimensional images is derived from analysis of multisensory stripping voltammetry electrochemical test system in the format of a "language".

Effective diagnostics through early disease detection implies simple procedures for initial patient examination, thereby reducing time and labor costs. In the line of the concept of metabolic profile, clinical chemistry is mostly concerned with analysis of body fluids. When conducting a comprehensive analysis of clinical chemistry is mainly limited to studies of the composition of the fluids of the human body [1].

A new approach to the analysis of volatile compounds is based on the use of "electronic nose" devices [2-4]. When using "electronic nose" and "electronic tongue" [5] each analyzed substance corresponds to some pattern of feedback system that 
enables multidimensional discriminate against various substances (or mixtures of substances) by comparing them to images formed in advance $\mathrm{N}$-dimensional image database [6]. A fairly complete list of models "electronic nose and electronic tongue" is presented in [7], [8]. A number of foreign and domestic firms made bids for Annex developed analytical tools for evaluating the quality of foodstuffs [9] Wednesday, environmental monitoring [10], as well as for use in medical diagnosing [11].

The effective dosage of a new ophthalmic medicine is determined from the concentration-time profile of the drug in lacrimal fluid. Many analytical problems are solved by electrochemical methods which are quite simple, quick, and effective techniques for reliable quantitative analysis. The method of multisensory stripping voltammetry (MSV) for analysis of organic substances was developed at the Frumkin Institute of Physical Chemistry and Electrochemistry, Russian Academy of Sciences. This method is used to detect changes in the electrochemical activity of metal cations in solutions; the changes are due to their interaction with organic substances [12-19]. Metal cations (components of the test system) that are able to form complex compounds with organic substances are introduced into a 0.05 solution of $\mathrm{KCl}$. The introduction of these metal cations is accompanied by peak dissolution currents on voltammograms: metal cations interact with organic compounds and resulting changes in metal dissolution currents are reflected on stripping voltammograms. These changes are evaluated either individually for each metal of the test system or integrally. Measurements are made on one indicator electrode, which has a definite advantage over those multisensor methods that use a set of electrodes. The method involves using a pre-created database to identify organic substances. It proved to be effective when determining the concentration of ophthalmic betaxolol [20-22]. In tear fluid. It was determined using a calibration function. We used the MSV method to build the concentration-time profile of betaxolol dissolved in tear fluid. It was shown that the concentration of betaxolol in tear fluid remains constant for 12 hours after instillation.

Glaucoma is one of the most severe forms of ocular pathology. After cataracts, glaucoma is the worldwide leading cause of blindness and low vision. In the Russian Federation, the share of glaucoma is $29 \%$ in the nosological structure of blindness and poor vision. The prevalence of glaucoma among the Russian population has increased by 2.8 times in recent years [23]. Glaucoma ranks first in the structure of primary visual disabilities in most regions of the Russian Federation. The main effect of most anti-glaucoma drugs is associated with reduction of intraocular pressure (IOP). One of the common IOP-lowering medications used as monotherapy or in combination with other drugs is Betoptic (betaxolol). Its chemical name is (2RS)-3-(2propylamino)-1-[4-[2-cyclopropylmethoxy)

lopropylmethoxy)ethyl]phenoxy]-propane-2-ol

hydrochloride. The pharmacotherapeutic group is antiglaucoma medication; it is a selective beta-1- adrenoblocker. The pharmacological action of the betaxolol drug is selective beta-1-adrenoblockade without internal sympathomimetic activity; the drug does not have a membrane-stabilizing (local anesthetic) effect. With topical application, betaxolol reduces both elevated and normal intraocular pressure by reducing the production rate of ocular fluid. The onset of the hypotensive effect is observed in $30 \mathrm{~min}$ after instillation, and the maximum ophthalmotonus decrease occurs in approximately $2 \mathrm{~h}$, according to the instructions for use of the drug. After a single instillation, the effect on ophthalmotonus persists for 12 h. Betaxolol does not decrease blood flow in the optic nerve compared toother beta-blockers. In addition, it does not cause miosis, spasm of accommodation, hemeralopia, or the effect of a "veil" over the eyes (in contrast to miotics). Regarding its pharmacokinetics betaxolol is highly lipophilic, resulting in good penetration through the cornea into the anterior chamber. The maximum concentration in the anterior chamber is observed $20 \mathrm{~min}$ after instillation. With topical use systemic absorption is low, the plasma concentrations is below the detection threshold $(2 \mathrm{ng} / \mathrm{mL})$. The drug is excreted mainly through the kidneys.

The popularity of betoptic has led to a set of its generics. The advantages of generics are low cost (due to the lack of costs on the elaboration, clinical trials and licensing fees), as well as the available results of clinical trials and accumulated experience of practical application of the drug (active ingredient) in the form of the original drug, which is copied by the generic versions. Despite the fact that generics are not original drugs, they must comply with requirements, i.e., they contain a ratio of active pharmaceutical ingredients, that of the qualitative and quantitative composition of their brand-name counterparts. It is necessary that the generic meets the requirements of the established standards. The production must comply with proper manufacturing practices. The generic must be equivalent to the original product in its degree and rate of absorption. A drug frequently has several analogues, but only those produced by different pharmaceutical companies. Therefore, the composition, and hence, their efficacy may differ. In addition, not all manufacturers of generic drugs comply to the requirements for generic production [24]. The Frumkin Institute of Physical Chemistry and Electrochemistry has developed a version of an electrochemical method for the analysis of organic substances: a multisensory stripping voltammetry method. This method measures the change in the electrochemical activity of metal cations in solution upon their interaction with organic substances [25, 26]. Metal cations, which have the ability to form complex compounds with organic substances, are introduced in solution of $0.05 \mathrm{M} \mathrm{KCl}$ (test system). These metals reveal the peaks of the dissolution currents on voltammograms. When a sample with the analyzed substance is introduced into the solution of a test system, metal cations interact with organic compounds, and their influence on the metal dissolution currents is recorded on a stripping voltammogram. These changes are 
determined for each of the metals of a test system or an integral evaluation of a change of the entire voltammogram is performed. Measurements are performed on a single indicator electrode, which has a significant advantage compared to multi-sensor methods using a range of electrodes. This method allows the identification of organic substances using a preliminary database.The effectiveness of this method has been shown for several ophthalmic medications: Visomitin, Betoptic, and Lanomax [27-30]. The concentration of Visomitin in the lacrimal fluid was measured based on a calibration relationship. The dynamics of changes in the Visomitin concentration in tear fluid over time were studied by multisensory stripping voltammetry; it was shown that its concentration significantly decreased in 2 h. Similarly, a possible change in the concentration of the Betoptic in the lacrimal fluid was investigated; it was shown that its concentration did not change 12 hours after instillation. The purpose of this study was to investigate the pharmacokinetics of generic forms of Betoptic, that is, Xonef, Betoftan, and Betalink EU using a multisensory stripping voltammetry method.

\section{Materials and methods}

The analyzer embodies a new approach using a solution containing various metal ions as an electrochemical testsystem, the ions being able interact with organic substances to form complex compounds [21-31]. All known E-tongue devices use a set of electrodes as sensors, therefore the reproducibility of characteristics of the multi-sensor systems is problematic, which affects the reliability and pattern recognition in a negative way. We propose enhancing the reliability and pattern recognition of our multi-sensor stripping voltammetry method through the use of metal cations, dissolved in the background electrolyte, as sensors. One electrode is used to record voltamperograms by the stripping voltammetry technique to obtain multidimensional patterns of analytes.

The test-system (background electrolyte) is a $0.05 \mathrm{M}$ $\mathrm{KCl}$ solution containing the metal cations such as $\mathrm{Zn} 2+$, $\mathrm{Cd} 2+, \mathrm{Pb} 2+, \mathrm{Cu} 2+\mathrm{Co} 2+, \mathrm{Hg} 2+$ as sensors. Thus an array of sensors is formed on one electrode allowing the deviceto be used as both E-tongue. The measurements have been done using planar electrodes (Autocom, Moscow), which represent polypropylene plates with working and auxiliary electrodes (carbon material) and silver-chloride reference electrode (Brown electrode) The voltamperograms (sensor outputs) recorded by the method of stripping voltamperometry are characterized by specific features and good reproducibility. The appearance of the voltamperograms change when different organic substances are added to the test-system. Each of the organic substances (or mixture of substances) produces specific changes, which allows their discrimination.

Measurements were made on a planar electrode. The test system solution consisting of $0.05 \mathrm{M} \mathrm{KCl}$ contained cations of metals $\mathrm{Zn} 2+, \mathrm{Cd} 2+, \mathrm{Pb} 2+, \mathrm{Cu} 2+\mathrm{Co} 2+$, and Hg2+ in a concentration of $5 \cdot 10-5 \mathrm{M}$. First, the test system solution was applied to the indicator electrode and a background stripping voltammogram was obtained. The potential of cathodic metal deposition was set to $-1.55 \mathrm{~V}$ (with respect to the silver chloride electrode), which was followed by a potential sweep of up to $0.3 \mathrm{~V}$ (Fig. 1, curve 1 ). In this work, the change in concentration has been studied in the tear fluid after instillation of the following Betoptic generic drugs: Xonef (Sentiss Pharma Pvt. Ltd., India), Betoftan (ROMPHARM Company, Romania), and Betalink EU (Unimed Pharma, the Slovak Republic).

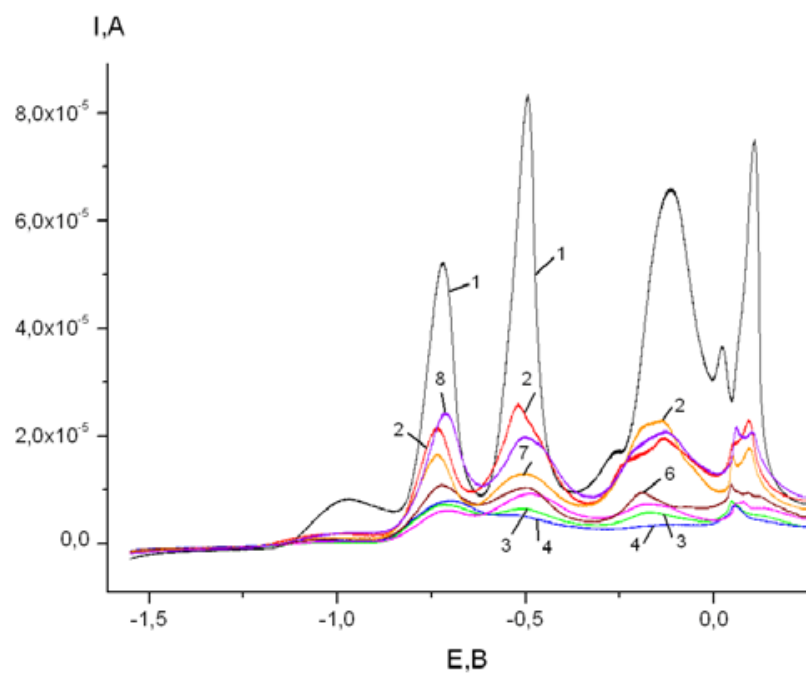

Fig.1. Stripping voltammograms of the test system with Betoftan in different concentrations: (1) test system; (2) lacrimal fluid of healthy people; (3) $4 \times 10-3 \%$ of Betoftan; (4) $3 \times 10-3 \%$ of Betoftan; (5) $2 \times 10-3 \%$ of Betoftan; (6) $1 \times 10$ $3 \%$ of Betoftan; (7) $0.5 \times 10-3 \%$ of Betoftan; (8) $0.1 \times 10-3 \%$ of Betoftan

Betoptic has a much more complex range of excipients, although the concentration of the active ingredient in all drugs is the same $(0.5 \mathrm{mg}$ of betaxolol hydrochloride). To conduct tests, $50 \mu \mathrm{L}$ of a test system consisting of $0.05 \mathrm{M} \mathrm{KCl}$ and a range of metal cations $\left(\mathrm{Zn}^{2+}, \mathrm{Cd}^{2+}, \mathrm{Pb}^{2+}, \mathrm{Cu}^{2+}, \mathrm{Co}^{2+}, \mathrm{Hg}^{2+}\right)$ at a concentration of 5 $\times$ 10-5 $\mathrm{M}$ for each cation were loaded at planar electrodes (OOONPP Avtokom, Moscow); stripping voltammetry at a athodic potential of $-1.55 \mathrm{~V}$ to deposit the metal ion on the electrode was performed with respect to a silver chloride reference electrode potential, in the positivegoing sweep of $0.3 \mathrm{~V}$; the resulting voltammogram was the background (Fig. 1, curve 1). The test system was removed from the electrode surface using filter paper. To study the effect of generics on the test system, $50 \mu \mathrm{L}$ of fresh solution of the test system and a disk of porous material (filter paper) with the generic drug in the required concentration were placed on the electrode and a stripping voltammogram was again recorded. To study the effect of tear fluid on the test system, an 8-mm diameter disc of pre-treated porous material (filter paper, which had been thoroughly rinsed in alcohol and distilled water and dried at a temperature of $80^{\circ} \mathrm{C}$ for $3 \mathrm{~h}$ ) was placed into the conjunctival sac of the eye. Next, $50 \mu \mathrm{L}$ of the test system was applied again onto the electrode and a paper disk with tear fluid 
extracted from the conjunctival sac was placed on the electrode. A stripping voltammogram of the lacrimal fluid was recorded under the same conditions as the background curves. While investigating the effect of generics on the lacrimal fluid after instillation, the generic solution was administered into the conjunctival sac and a disk of filter paper was then placed there. After a certain time, the paper disc was removed from the conjunctival sac and placed on an electrode with a test system applied to it. Measurements were carried out after $30 \mathrm{~min}, 1 \mathrm{~h}$ and then every hour for $12 \mathrm{~h}$ after instillation of the drug.

\section{Results and discussion}

The effect of betoftan in different concentrations on the test-system. Figure 1 presents stripping voltammograms recorded when subjecting the test system to different concentrations of Betoftan. It is seen that with increasing drug concentration the lead currents decreased: from 19 to $12 \mu \mathrm{A}(\varphi=-0.53 \mathrm{~V})$ and cadmium from 20 to $11 \mu \mathrm{A}(\varphi=-0.75 \mathrm{~V})$. The currents of zinc, cobalt, and mercury almost did not change. Other generics with the same content of the active ingredient (betaxolol hydrochloride, $5 \mathrm{mg}$ ): Xonef and Betalink EU, demonstrated a similar effect on the test system. Thus, it has been shown that the method of multisensory stripping voltammetry can be used to measure the concentration of the generics in a test system.

The effect of the lacrimal fluid from healthy people on the test system. After recording the background curves using the above method (Fig. 2, curve 1) a voltammogram of tear fluid was recorded under the same conditions. Figure 2 (curve 2) shows the corresponding averaged voltammogram of tear fluid obtained from ten healthy people. The individual spread of voltammograms was $12 \%$.

The time-dependent content of betoftan in the lacrimal fluid after instillation. One drop of Betoftan was in stilled into the conjunctival sac of the eye and an $8 \mathrm{~mm}$-disk of filter paper was placed there. After certain periods of time, the paper disk was removed from the conjunctival sac and placed on the electrode with the test system applied to it. Measurements were carried out after $30 \mathrm{~min}, 1 \mathrm{~h}$, and then every hour for $12 \mathrm{~h}$ after instillation of the drug. It has been found that the dissolution currents of metals did not change at the time of exposure to Betoftan from $30 \mathrm{~min}$ to $12 \mathrm{~h}$. The corresponding voltammogram is shown in Fig. 2 (curve3). The results show that the concentration of Betoftan in the tear fluid did not change over $12 \mathrm{~h}$.

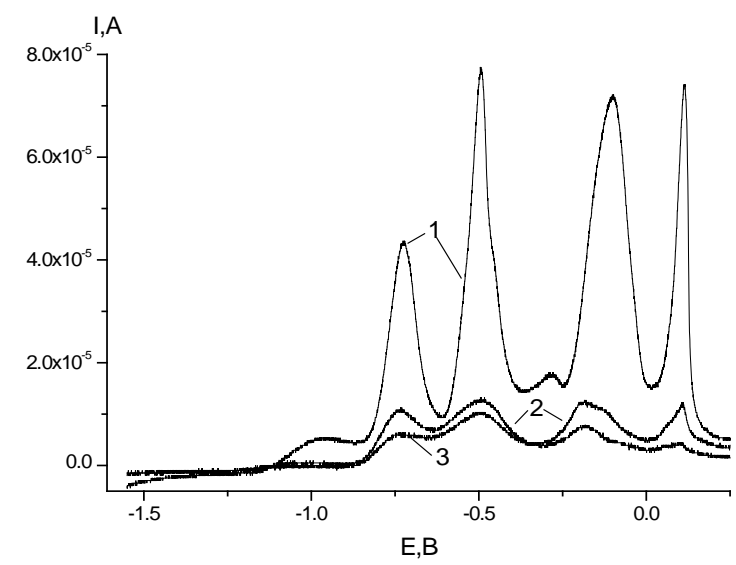

Fig. 2. Stripping voltammograms showing the effect of lacrimal fluid and Betoftan on the test system on the test system: (1) test system, (2) lacrimal fluid, (3) tear fluid after instillation of Betoftan.

Therefore, the drug is quite stable over time and continues to have an effect on the tear fluid $12 \mathrm{~h}$ after instillation, as well as on the cornea of the eye. The timedependent concentrations Xonef, and Betalink EU were investigated in a similar way in the lacrimal fluid after instillation.

Table 1. The effects of the Betoptic and its generics with the same concentration of the active ingredient on the test system after instillation

\begin{tabular}{|l|l|l|l|l|l|l|}
\hline \multirow{2}{*}{ Lacrimal fluid } & \multicolumn{5}{|c|}{ Peaks of metal dissolution currents, $\mu \mathrm{A}$} \\
\cline { 2 - 7 } & $\mathrm{Zn}$ & $\mathrm{Cd}$ & $\mathrm{Pb}$ & $\mathrm{Cu}$ & $\mathrm{Co}$ & $\mathrm{Hg}$ \\
\hline Healthy people & 1,6 & 14,6 & 14,0 & 13,2 & 13,0 & 12,8 \\
\hline $\begin{array}{l}\text { Patients with } \\
\text { glaucoma after } \\
\text { instillation of } \\
\text { Betoptic }\end{array}$ & 1,6 & 11,2 & 12,4 & 10,0 & 5,6 & 4,6 \\
\hline $\begin{array}{l}\text { Patients with } \\
\text { glaucoma after } \\
\text { instillation of } \\
\text { Betoftan }\end{array}$ & 2 & 10 & 13 & 7,3 & 6,1 & 5,5 \\
\hline $\begin{array}{l}\text { Patients with } \\
\text { glaucoma after } \\
\text { instillation of } \\
\text { Xonef }\end{array}$ & 2 & 9,5 & 11,5 & 10,4 & 5,0 & 4,2 \\
\hline $\begin{array}{l}\text { Patients with } \\
\text { glaucoma after } \\
\text { instillation of } \\
\text { Betalink }\end{array}$ & 2 & 11 & 12 & 9,5 & 6.0 & 5 \\
\hline
\end{tabular}

Table 1 shows the effect of the Betoptic and its three generics with the same concentration of the active ingredient on the test system (betaxolol hydrochloride, 5 mg) $12 \mathrm{~h}$ after instillation. The same effect of the generics with the same concentration of the active 
ingredient on the test system indicates that betaxolol, rather than auxiliary components included in the formulations, has the major effect on the test system. It is noted that use of the generics caused burning and tingling sensations in the conjunctiva in the studied subjects upon instillation.

The dissolution currents of metals decrease 4-7 times. This is due to the fact that organic substances of tear fluid are complexing agents. .

\section{Statistical Data Processing}

A Voltamperogram is Multidimensional and divided into $\mathrm{N}$-dimensional image, the amount of which depends on the complexity of the investigated system. Thus formed N-dimensional image object.

Data Dimensionality Reduction. The next step is to group processing correlated sensors into clusters by reducing the dimensionality of data with the subsequent allocation of $\mathrm{M}$ bulk of characterizing the cluster information. $\mathrm{M}$ varied to achieve maximum discriminatory ability.

There are many algorithms to reduce the dimensionality of the data, some of which were tested in the study: Image of Primary Data The result of the operation is voltamperogram (Fig 2)-current dependence of electrode potential, changing on linear time (sweep rate capacity). The peaks correspond to oxidation of metals test systems. Digital values (453 points) coming into the program for further processing in the form of a file from which to retrieve the value of the current. A voltamperogram factor analysis, principal component analysis, cluster analysis, Fourier transform [32].

\section{Discrimination Algorithm}

The purpose of discriminatory analysis is attributing the object under study to a certain group/class by its characteristics in an optimal way, minimizing expected losses and the probability of misclassification. Discriminatory analysis, as part of statistical multiparameter analysis, comprises methods for classification of multidimensional objects through the use of available training samples.

Training samples were obtained by measuring parameters of known analytes to be subsequently stored in the database. A similarity measure is the square of the Mahalanobis distance, which shows how close the object is to the centroids of the groups of known samples in the space of canonical roots. The results of the discrimination are visually presented as a graph in the space of the first and second canonical roots, the known analytes being depicted as clouds of points surrounded by ellipses and the sample under study as a point.

Thus, the discriminatory analysis allows the objects under study to be classified by a set of group/class attributes The values of current were recorded in the database, assigned to one of three groups: "TEAR", "BET", or "TEST", indicating presumably healthy patients, or glaucoma patients, or the test-system (reference sample), respectively.

The statistics software package Statistica 7.0 was used for data processing.

\section{Conclusions}

Here we have shown that

(1) It has been shown that compared to a voltammogram of Tear fluid from a healthy person, the effects of Betoptic, Xonef, Betoftan, and Betalink were mainly observed for mercury and cobalt: the dissolution currents of these metals decreased from 12 to $6 \mu \mathrm{A}$ for cobalt and from 12 to $5 \mu \mathrm{A}$ for mercury.

(2) The studied drugs are quite stable over time and continue to exert an effect on the Tearl fluid $12 \mathrm{~h}$ after instillation.

(3) The use of the generic forms of Betoptic (Xonef, Betoftan, and Betalink EU) caused some minor discomfort upon instillation in the form of the burning or tingling sensation in the area of the conjunctiva.

(4) The method of multisensory stripping voltammetry allows one to analyze the time-dependent effect of various ophthalmic drugs on the Tear fluid in the Electronic language format.

\section{References}

1. A. D’Amico, C. Di Natale, R. Paolesse, et al., Sensors and Actuators B: Chemical, 130, 458-465 (2008) http://dx.doi.org/10.1016/j.snb.2007.09.044

2. D. Pickel, G. Manucy, D. Walker, Applied Animal. Behaviour Science, 89, 107-116 (2004) http://dx.doi.org/10.1016/j.applanim.2004.04.008

3. C.M. Willis, S.M. Church, C.M. Guest, et al., British Medical Journal, 329, $712 \quad$ (2004) http://dx.doi.org/10.1136/bmj.329.7468.712

4. M. McCulloch, T. Jezierski, M. Broffman, et al., Integrative Cancer Therapies, 5, 30-39 (2006) http://dx.doi.org/10.1177/1534735405285096

5. P. Pelosi, K.C. Persaud, In Sensors and Sensory Systems for Advanced Robotics. In: Dario, P., Ed., Springer-Verlag, Berlin, 361 (1988)

6. S. Ampuero, J.O. Bosset, Sensors and Actuators B: Chemical, 94, 1-12 (2003) http://dx.doi.org/10.1016/S0925-4005(03)00321-6

7. D. James, S.M. Scott, Z. Ali, W.T. O’Hare, Microchimica Acta, 149, 1-17 (2005) http://dx.doi.org/10.1007/s00604-004-0291-6

8. N.V. Dolgopolov, M. Yablokov, Peace and Security, 3, 54 (2007) [in Russian]

9. M. Aleixandre, J. Lozano, J. Gutirerrez, et al., Sensorsand Actuators B: Chemical, 131, 71-76 (2008)

http://dx.doi.org/10.1016/j.snb.2007.12.027 
10. O. Helli, M. Sia, Sensors and Actuators B, 103, 403408 (2004) http://dx.doi.org/10.1016/j.snb.2004.04.069

11. E.R. Thaler, Laryngoscope, 112, 1533-1542 (2002) http://dx.doi.org/10.1097/00005537-20020900000002

12. D. James, S.M. Scott, Z. Ali, W.T. O’Hare, Microchimica Acta, 149, 1-17 (2005) http://dx.doi.org/10.1007/s00604-004-0291-6

13. N.V. Dolgopolov, M. Yablokov, Peace and Security. 3, 54 (2007) [in Russian]

14. M. Aleixandre, J. Lozano, J. Gutirerrez, et al., Sensors and Actuators B: Chemical, 131, 71-76 (2008) http://dx.doi.org/10.1016/j.snb.2007.12.027

15. O. Helli, M. Sia, Sensors and Actuators B, 103, 403408 (2004) http://dx.doi.org/10.1016/j.snb.2004.04.069

16. E.R. Thaler, Laryngoscope, 112, 1533-1542 (2002) http://dx.doi.org/10.1097/00005537-20020900000002

17. W.A. Groves, E.T. Zellers, G.C. Frye, Analytica Chimica Acta, 371, 131-143 (1998) http://dx.doi.org/10.1016/S0003-2670(98)00294-3

18. C. Di Natale, A. Macagnano, E. Martinelli, et al., Biosensors and Bioelectronics, 18, 1209-1218 (2003) http://dx.doi.org/10.1016/S0956-5663(03)00086-1

19. W. Cao, Y. Duan, ClinicalChemistry, 52, 800-811 (2006) http://dx.doi.org/10.1373/clinchem.2005.063545

20. V.P. Lukovtsev, A.N. Doronin, N.V. Lukovtseva, V.A. Semenov, V.M. Ganshin, Electrochemistry, 45, 869-872 (2009) [in Russian]

21. V.N. Andreev, V.M. Ganshin, A.N. Doronin, et al., Patent of the Russian Federation No. 2375705 (2008) [in Russian]

22. I.I. Kolesnichenko, V.M. Ganshin, A.L. Kluev, et al., Proceeding of 4th International Scientific and Practical Conference. Publishing House of the Polytechnic University, Saint-Petersburg, 189 (2013) [in Russian]

23. .Nesterov, Glaucoma (Mediform, Moscow, 2014)

24. I. B. Bondareva, Klin. farmokinet., 1(2), 7 (2005)

25. I.I. Kolesnichenko, A.L. Klyuev, V.M. Ganshin,et al., Prot. Met. Phys. Chem. Surf., 50(4), 543 (2014)

26. L.M. Balashova, I.I. Kolecnichenko, E.P. Kantarzhi, Klin. Gepontol., 23(9-10), 6 (2017)

27. I.I. Kolesnichenko, A.N. Doronin, E.P. Kantarzhi, L.M. Balashova, Vestn. MGTU im. N.E. Baumana, Ser. Estestv. Nauki, 2, 107 (2018)

28. L.M. Balashova, V.A. Namiot, I.I. Kolecnichenko,et al., Biophysics, 63(4), 655 (2018)

29. I.I. Kolesnichenko, V.M. Ganshin, et al. Proceeding of 3th International Scientific and Practical Conference. Publishing House of the Polytechnic
University, Saint-Petersburg, 164-173 (2011) [in Russian]

30. I.I. Kolesnichenko, L.M. Balachova, E.P. Kantarzhi, American Journal of Analitical Chemistry, 7, 588596 (2016)

31. L.M. Balashova, V.A. Namiot, I.I. Kolesnichenko etc. Biophysics, 65(6), 1211-1218 (2020)

32. .A.A. Khalafyan, Statistica 6. Statistical Data Analysis. 3rd Edition, Moscow. (2007) [in Russian] 